\title{
Exploring the impact of the 'new' ParticipACTION: overview and introduction of the special issue
}

\author{
Guy Faulkner, PhD (1); Lira Yun, MS (2); Mark S. Tremblay, PhD (3); John C. Spence, PhD (2)
}

\author{
This evidence-informed policy brief has been peer reviewed.
}

\begin{abstract}
ParticipACTION is the Canadian physical activity communications and social marketing organization first launched in the fall of 1971 and then ceased operations in 2001 . ParticipACTION was relaunched in 2007.

Framed as a public health natural experiment, evidence was collected from a populationbased survey of knowledge, awareness, understanding of physical activity, and physical activity levels among Canadians (individual level), and key informant surveys and interviews examining capacity, readiness and advocacy for physical activity promotion among physical activity organizations (organizational level).
\end{abstract}

The purpose of this paper is to first provide an overview of some of the major initiatives undertaken by the 'new' ParticipACTION that may have contributed to any changes at these individual or organizational levels. Second, the paper sets the stage for the three empirical papers in this special series reporting follow-up results.

Keywords: natural experiment, physical activity, organizational capacity, awareness

\section{Introduction}

It is well established that greater physical activity and lower sedentary behaviour are associated with a variety of positive health outcomes such as lowered risk for cardiometabolic disease and obesity, and improved skeletal and mental health, regardless of age, gender or ethnicity. ${ }^{1-3}$ Nevertheless, only $15 \%$ of adults and $9 \%$ of children and youth are meeting current physical activity guidelines., ${ }^{4,5}$ Further, adults are sedentary for about 9.5 hours per day, and children and youth for about 8.5 hours. ${ }^{4,5}$

Several government bodies and not-forprofit organizations have attempted to reverse this trend through physical activity promotion initiatives. ${ }^{6}$ ParticipACTION is a well-known Canadian physical activity social marketing organization that was created in 1971. During its initial 30-year operation, ParticipACTION was considered internationally as successful as these organizations with many award-winning campaigns (e.g. see Rootman \& Edwards [2004] for an overview ${ }^{7}$ ) particularly in that it "delivered clear messages, enhanced community awareness of physical activity and recreation, and fostered communitybased partnerships." However, due to funding cuts, it ceased operations in $2001 .{ }^{9}$ In February 2007, Sport Canada and the Public Health Agency of Canada announced funding for the relaunch of a "new" ParticipACTION. The new mandate of ParticipACTION was to provide leadership in facilitating collaborations, and in initiating social marketing campaigns to foster a social movement that inspires and supports Canadians to move more. ${ }^{10}$ The focus of the new ParticipACTION was on social marketing, communications and partnership synergy rather than physical activity program delivery. More details about the history and the structure of the relaunched ParticipACTION are provided by Latimer-Cheung, Murumets, \& Faulkner. ${ }^{11}$

As described by Tremblay and Craig, ${ }^{10}$ in response to the relaunch of ParticipACTION
Highlights

- This paper provides a summary of key initiatives of the 'new' ParticipACTION since its relaunch in 2007.

- This sets the context for empirical studies exploring the impact of ParticipACTION in Canada.

in January 2007, a "rapid response research team" was convened to explore opportunities for assessing the impact of the new ParticipACTION in the form of a natural experiment. Through support from the Canadian Institutes of Health Research (CIHR), this team collected baseline data before ParticipACTION began formal operations. This was a unique research opportunity, as despite its perceived success, limitations in evaluation designs of the original ParticipACTION have impeded full understanding of its impact. Specifically, formal evaluation techniques designed to appraise public health programs were limited at the time of ParticipACTION's launch. $^{8}$ To rectify this evaluation gap, baseline data were collected on individual-level awareness of the brand, campaign recall, knowledge, understanding and physical activity behaviours before and during the early period after the relaunch of ParticipACTION. ${ }^{12}$ Baseline data were also collected at an organizational level to assess the future impact of a sustained campaign through ParticipACTION on the overall capacity of the physical activity sector in Canada. ${ }^{13,14}$ These data have been published in seven peerreviewed manuscripts with the majority presented in a special issue of the International Journal of Behavioral Nutrition and Physical Activity (see Tremblay \& Craig $^{10}$ for an overview).

\section{Author references:}

1. School of Kinesiology, University of British Columbia, Vancouver, British Columbia, Canada

2. Faculty of Kinesiology, Sport, and Recreation, University of Alberta, Edmonton, Alberta, Canada

3. Healthy Active Living and Obesity Research Group, Children's Hospital of Eastern Ontario Research Institute, Ottawa, Ontario, Canada

Correspondence: Guy Faulkner, School of Kinesiology, University of British Columbia, 2146 Health Sciences Mall, Room 4606, Vancouver, BC V6T 1Z3; Tel: 604-822-2990; Fax: 604-822-6842; Email: guy.faulkner@ubc.ca 
In 2012, this research team received CIHR funding to collect follow-up data five years after the relaunch of ParticipACTION. The purpose of this special series of papers, published in Health Promotion and Chronic Disease Prevention in Canada, is to present evidence on the short-term impact of ParticipACTION at the individual level (in terms of population awareness, attitudes, behaviour), and at the organizational level (in terms of organizational capacity, readiness and advocacy regarding physical activity promotion). To contextualize those empirical studies, this introductory paper will first provide an overview of some of the major initiatives undertaken by the "new" ParticipACTION that may have contributed to any changes at these individual or organizational levels.

\section{The 'new' ParticipACTION}

The 'new' ParticipACTION identified three strategic priorities: communications, capacity building, and knowledge exchange. ParticipACTION's communications objectives included 1) delivering messages through multimedia for the purpose of raising awareness, educating, inspiring, and supporting physical activity, and 2) coordinating communications to ensure consistent, unified messaging across and within the physical activity sector. ParticipACTION's capacity building objectives included a) leveraging strengths within the physical activity sector by forging partnerships with and between organizations committed to promoting physical activity and sport participation in Canada, and b) supporting and managing the development and implementation of physical activity and sport participation initiatives (but not delivering programs). ParticipACTION's objective for knowledge exchange was to position itself as a hub of information, data, and research related to physical activity and sport participation in Canada. To facilitate knowledge exchange, ParticipACTION initially established three advisory groups: a research advisory group (RAG), a policy advisory group, and a marketing and communications advisory group. Knowledge exchange and mobilization was also supported more broadly by the development of the ParticipACTION Partnership Network (PPN). The PPN is a network of organizations dedicated to physical activity and sport participation and is a forum for increasing awareness of and access to resources, initiatives, and expertise within the physical activity sector.

Underpinning these three strategic priorities was a commitment by ParticipACTION to ongoing evaluation of its activities to both inform its own development and also create new knowledge. ParticipACTION conducts regular and ongoing evaluations of all its activities. This evidence is used to demonstrate accountability to funders and to build a strong case when seeking new funding opportunities. The availability of data from specific initiatives and campaigns has also provided an opportunity to generate new research knowledge about the effectiveness of physical activity and sport participation promotion initiatives at a population level. ParticipACTION employs a professional market research agency to conduct surveys of the general population and these data have been made available to members of the RAG to evaluate many of its initiatives. ParticipACTION data are also available on request by independent researchers subject to approval of ParticipACTION and the Chair of the RAG. This openness has the potential to benefit ParticipACTION through additional and often independent research outputs; the sector (by sharing research findings publicly); and the individual researchers (by allowing access to data often restricted for internal use only).

Table 1 presents an overview of some of the major programs and social marketing campaigns initiated by ParticipACTION between 2007 and 2015. The social marketing campaigns were focussed on message communication using a range of traditional (e.g. television) and new internet-based mediums. Program initiatives also had a communication element that had an explicit focus on capacity building in collaboration with other sector partners in program delivery. The next section describes some of these larger initiatives for which peer-reviewed published research has been generated.

\section{Communications}

Social marketing campaigns have been at the forefront of ParticipACTION's knowledge dissemination strategy. To raise awareness of, and encourage regular physical activity participation, ParticipACTION has launched five national campaigns (see Table 1). Unlike ParticipACTION's prerevitalization (1971 to 2001) campaigns, in which sport participation and structured exercise were prominently advocated by spokespeople, the new ParticipACTION campaigns focused on promoting physical activity in daily life and making physical activity part of Canadian culture.

\section{Get Inspired. Get Moving}

The new ParticipACTION's first mass media campaign was launched in October 2007. The "Inactive Kids" campaign was designed to increase awareness of, and create a sense of urgency, about the low levels of physical activity among Canadian children. ParticipACTION's second campaign, "Get Inspired. Get Moving," was first aired in 2009 and ran intermittently over a period of 33 weeks until 2010 with 1200 Gross Rating Points (GRPs), representing a percent of the target reached multiplied by the exposure frequency in the English media and 864 GRPs in the French media. Six advertisements were developed based on solicited stories from members of the general public representing diverse groups (i.e. gender, age, family, ethnicity, and ability). The development of the campaign messages was guided by a theoretical framework, the hierarchy of effects model (HOEM), which premises that campaign effects occur in a chain of stages from the awareness of the campaign, and then progresses through intermediate outcomes (e.g. knowledge, saliency, attitudes, self-efficacy, intention), and to distal outcomes such as behavioural changes. ${ }^{15,16}$

Craig and colleagues ${ }^{16}$ examined data from an online representative panel of Canadians $(\mathrm{N}=1110)$ to evaluate the communication effects of the "Get Inspired. Get Moving” campaign. Specifically, they measured campaign specific cognitive variables based on the HOEM, i.e. saliency and cognitive engagement of the campaign, campaign-specific self-efficacy and trialing behaviour, and investigated whether these variables were related to overall self-efficacy for physical activity, intention to be active, and current activity level. All the campaign specific variables were found to be predictors of subsequent effects (saliency $\rightarrow$ cognitive engagement $\rightarrow$ campaign specific self-efficacy $\rightarrow$ trialing behaviour). Furthermore, campaignspecific self-efficacy was associated with overall self-efficacy, which was in turn associated with overall future intention to be active. Findings highlighted the usefulness of incorporating theoretically informed 
TABLE 1

Major programs and social marketing campaigns of ParticipACTION (2007-2015)

\begin{tabular}{ll}
\multicolumn{1}{c}{ Programs } & \multicolumn{1}{c}{ Date } \\
\hline Sunlife Inspire the Nation & Summer 2009 \\
\hline Sports Day in Canada & $2010-2015$ \\
\hline Sneak it in & 2011 -present \\
\hline $\begin{array}{l}\text { ParticipACTION Teen Challenge } \\
\text { (previously SOGO Active) }\end{array}$ & 2008-present (contract ended in 2017) \\
\hline RBC Learn to Play & 2014-present (current contract ends in 2018) \\
\hline \multicolumn{1}{|c}{ Social marketing campaigns } & \\
\hline Inactive kids & October 2007-March 2008 \\
\hline $\begin{array}{l}\text { Get inspired. Get moving. (Icon) } \\
\text { Get Inspired. Get Moving. (Animated spots) }\end{array}$ & November 2008-March 2009 \\
\hline $\begin{array}{l}\text { Think Again } \\
\text { Bring Back Play (including Funmobile and } \\
\text { Longest Day of Play) }\end{array}$ & January 2011-March 2012 \\
\hline $\begin{array}{l}\text { Bring Back Play (year two, including Bring Back } \\
\text { Winter Play, Unplug and Play, and Longest Day } \\
\text { of Play) }\end{array}$ & November 2013-June 2014 \\
\hline \begin{tabular}{l} 
Make Room for Play \\
\hline
\end{tabular} & \\
\hline
\end{tabular}

models in the development and the evaluation of social marketing campaigns.

\section{Think Again}

ParticipACTION's next population-level campaign, "Think Again," was aired on television in three waves: from January to March 2011, June to August 2011, and January to March 2012. The campaign coincided with the release of the Physical Activity Guidelines for Canadians updated in 2011 by the Canadian Society for Exercise Physiology (CSEP), a partnering organization with ParticipACTION. ${ }^{17}$ The focus of this campaign was on parents of children aged 5 to 11 years. The campaign aimed to motivate parents, and in particular mothers, to get their children active by increasing parents' awareness that their children may not be active enough to meet the guidelines. It focused on increasing the awareness of parents regarding other children's physical activity levels, thus motivating them to take action to support their children to be more active. Advertisements with the key message, "THINK AGAIN, Fact is kids need at least 60 minutes of physical activity per day. Every day," were aired on various types of media outlets, including television, print, and online. ${ }^{18,19}$

The evaluations of the "Think Again" campaign were administered by the RAG, either using secondary survey data collected by Angus Reid Public Opinion on behalf of ParticipACTION, or using primary data collected by the group. At least six peerreviewed papers were published using various approaches to identify campaign effects and inform future social marketing campaigns. ${ }^{18-22}$ Rhodes et al. ${ }^{21}$ examined the role of parents $(\mathrm{N}=663$ mothers $)$ to support their children's physical activity based on the theory of planned behaviour which postulates that individuals' proximal determinant of behavior is their intention to perform that behaviour and intention is predicted by affective or instrumental evaluation of the behaviour (i.e. attitude), perceived social pressure (i.e. subjective norm), and easiness or difficulty of performing the behaviour (i.e. perceived behavioural control). The results demonstrated that attitudes toward children's physical activity and parental support, and control over support, were associated with mothers' intention to support children's physical activity, which consequently predicted the physical activity level of their children. Furthermore, regardless of intentions to support, or antecedent positive attitudes about child activity and support, the control that mothers have over supporting child activity was found to predict physical activity.

Berry and colleagues ${ }^{22}$ conducted an experimental study to examine mothers' intention to support children's physical activity after viewing the campaign advertisements with a focus of identifying the role of certain cognitive variables such as believability, agreement, involvement, and attention to the campaign advertisements. The elaboration likelihood model of persuasion (ELM) was selected as a theoretical model to determine if implicit responses (i.e. unconscious reactions without time for reflection such as implicit agreement) and reflective responses (i.e. conscious reactions such as explicit believability and involvement) to the advertisement messages could differentially predict cognitions (i.e. attitudes, intentions) related to the behaviour promoted by the campaign. Mothers $(\mathrm{N}=102)$ who participated in the study were asked to view one of the "Think Again" advertisements and complete the implicit agreement task followed by the questionnaires. The results demonstrated that mothers who paid attention to the campaign message and were concerned about their own children's physical activity were more likely to make their children participate in more physical activity. Furthermore, the results confirmed that there was a gap between mothers' perceptions (implicit agreement) and realities regarding their children's physical activity levels. Many mothers believed their children get enough activity, but only a few reported that their children were active every day of the week.

To build upon this disconnect between parents' perceptions and realities relating to their own children's physical activity, Faulkner and colleagues ${ }^{18}$ interviewed 24 parents (12 mothers and 12 fathers) of children aged 5 to 11 years to further explore their perceptions of the campaign. The Think Again public service announcement (PSA) was generally well-received by the parents. Most notably, though some parents thought the PSAs facilitated reflection on their children's physical activity levels, the majority believed that their children were engaged in sufficient amounts of physical activity each day even though their children were not necessarily meeting physical activity guidelines. Barriers to parents' support of children's physical activity included job and time constraints, and misconceptions about intensity levels and key physiological indicators of certain physical activities. ${ }^{18}$ More creative approaches may be needed in addressing this continuing disconnect in perceptions between sufficient and recommended levels of physical activity. 
The overall impact of "Think Again” as a mass media campaign was examined by Gainforth and colleagues. ${ }^{23}$ Guided again by the HOEM, this study focused on identifying the relationships with proximal (e.g. awareness of a campaign, beliefs about the behaviour, intentions to engage in the behaviour) and distal factors (e.g. behavioural change). Among participants recruited from an existing online panel at two independent time points, parents with at least one child, aged 5 to 11 years, were included in the study. Their survey responses explaining changes in both proximal and distal outcomes in the HOEM as well as the goal of the campaign (i.e. parental support and child physical activity) supported the research hypothesis; compared with parents unaware of the campaign, parents who were aware of the campaign showed greater knowledge of physical activity guidelines, higher outcome expectations about their children engaging in physical activity, stronger intentions to help their child meet the guidelines, and more parental support behaviours. Furthermore, parents who were aware of the campaign had greater perceived behavioural control to influence their child's physical activity participation compared with unaware counterparts. Parental awareness of the campaign was not associated with children meeting physical activity guidelines which implied that achieving success in a mass media health campaigns is difficult as HOEM outcomes become more distal.

Taking a social marketing approach, Deshpande and colleagues ${ }^{19}$ conducted a post-test only experimental study to evaluate the effect of message formats (dynamic vs. static) on the advertisement of the Think Again campaign. A nationally representative sample of 663 Canadian mothers of children, aged between 5 and 11 years, were randomly assigned to receive either a dynamic version of the advertisement delivered via video format or a static version of the advertisement delivered via image format. After viewing the assigned advertisement, they were asked to complete the questionnaires about campaign recall, ad liking, motivation to respond to the ad (i.e. assist one's child to get at least $60 \mathrm{~min}$ of physical activity every day), and their support behaviours. Participants who watched the video format advertisement showed higher advertisement recall, theme recall, and message recall than participants who viewed the image format advertisement.
Positive responses to advertisements and motivation to help children get 1 hour of physical activity daily were also slightly higher among participants who watched the video advertisement. The findings suggest the importance of selecting an appropriate media type and message format to deliver a message in a social marketing campaign.

Finally, Jarvis and colleagues ${ }^{22}$ examined the role of the ParticipACTION brand in the campaign effects. The study focused on the examination of ParticipACTION brand equity which is defined as a set of associations that consumers form with a brand (including brand awareness, perceived quality, leadership and popularity, organizational associations, and brand personality), and its impacts on campaign effects, such as, intentions to engage in behaviours (i.e. parental support for child physical activity) promoted by the campaign. A cross-sectional design with different samples of participants (with children between 5 and 11 years) surveyed at three different time points of the "Think Again" campaign was applied. Supporting the hypothesis, a positive association between message exposure and campaign brand equity as well as between brand equity and parental support were found. Furthermore, structural equation modeling revealed a significant mediation effect of brand equity on the relationship between message exposure and parental support. Such results implied the importance of building brand equity with advertisement viewers by maintaining brand exposure throughout the campaign. ${ }^{22}$

The findings from these studies examining the "Think Again" campaign present some significant implications for developing family-based interventions and campaigns to promote physical activity: 1) emphasizing the importance of providing support and raising the perceived control of parents over supporting their children to be $\operatorname{active}^{21}$;2) shifting towards changing societal beliefs about the amount of physical activity necessary for children ${ }^{20}$; 3) providing accurate information about the physiological indicators and intensity levels of certain activities, promoting participation in non-traditional forms of activity, and creating tips to effectively support children's physical activity ${ }^{18}$; 4) implementing future mass media campaigns concurrently with policies, environmental changes, and appropriate programs to expand positive outcomes ${ }^{24}$; and, 5) the medium through which the message is delivered $^{19}$ and perceptions of the sponsoring organization ${ }^{22}$ have an impact of outcomes of interest such as message awareness. These insights were shared directly with the ParticipACTION leadership team and have been taken into consideration for future social marketing campaigns and initiatives as well as in content development for the website, newsletters, blogs, etc.

\section{Make Room for Play}

In 2015, ParticipACTION developed a social marketing campaign, called "Make Room for Play," to increase the awareness of the importance of play as a source of physical activity and to highlight the value of replacing screen time with outdoor play time. ParticipACTION augmented the national media plan with a British Columbia-specific media purchase (cobranded between ParticipACTION and British Columbia). Four thirty-second ParticipACTION advertisements, offered in both English and French, were aired via television (1300 planned and 2422 estimated GRPs in Vancouver, and 2141 unplanned GRPs in other regions in BC), cinema (23 locations/65 screens), and digital (ParticipACTION website, Youtube, and Facebook) between January 12 and March 31, 2015. Based on a survey of over 125000 Canadians, carried out by Angus Reid Forum, the campaign showed significant impact on mothers in British Columbia, with $50 \%$ advertisement recall. Moreover, $90 \%$ of viewers agreed that the ads made them feel that screen times take away opportunities for active play, and that children should decrease their screen time. The campaign was found to evoke mothers' concern over the amount of time their kids spend on screen time and motivated them to take action to increase their child's physical activity. ${ }^{25}$ This is the first Canadian mass media campaign addressing the issue of screen time among children, and future evaluations are planned to assess its impact.

\section{Capacity building}

Engagement with, and capacity building in, communities and the larger physical activity sector has been one of the main foci of the new efforts undertaken by ParticipACTION. These have mostly involved strategic partnerships with government, non-profit, or profit-based organizations to advocate for the importance of increasing physical activity to the public, and to 
exchange resources among partners to provide environments in which all Canadians can pursue active lifestyles. Community engagement initiatives have been implemented in a range of settings, such as local communities, workplaces, schools, and homes, reaching all groups of Canadians regardless of region, age, gender, ethnicity, and ability. In the following, a description of a sample of initiatives is presented with most evaluations relying on unpublished, internal reports.

\section{Teen Challenge}

In 2008, ParticipACTION, in partnership with Coca Cola Canada, launched its first national physical activity program-the Teen Challenge (initially named SOGO Active). The overall goal of the program was to help Canadian teenagers aged 13 to 19 years to become more active by providing micro-grants (up to \$500 CAD), relevant programming, and leadership opportunities to local community organizations including leagues, recreational centers, churches, and schools. A total of 503,979 teens from 5,892 community organizations across Canada have registered in the program, and 4,665 physical activity grants (approximately $\$ 5.5 \mathrm{mil}$ lion CAD) have been deployed. Microgrants were used in a number of ways such as buying equipment, hiring instructors, or renting space for activities.

An evaluation report on Teen Challenge showed that the program has increased the capacity of organizations to deliver sport and physical activity programs in communities across Canada. ${ }^{26}$ Research conducted by Tamminen and colleagues (2014) revealed that the micro-grant program has been useful in exposing teenagers to a variety of physical activities, and has had a positive impact on the organizations, teen participants, and surrounding communities. ${ }^{27}$ The program has especially helped to relieve issues of inequity between urban and rural communities; i.e. the Teen Challenge enabled youth in small rural communities to be engaged in various types of sports and activities. Overall, the evaluation showed the potential of a micro-granting program to help communities build capacity to provide active environments to teens, and suggested future initiatives for leveraging micro-grants to sustain the program.

\section{RBC Sports Day in Canada}

ParticipACTION launched its largest program, "RBC Sports Day in Canada" (SDIC), in 2010. Title sponsored by the Royal Bank of Canada (RBC), in collaboration with True Sport (www.truesportpur.ca) and the Canadian Broadcasting Corporation (CBC; www.cbc.ca), the program was intended to invite local organizations, communities, clubs, schools, and workplaces in Canada to hold "Sports Day" - an annual event celebrating the role of sport within communities and promoting sport participation across the country. ParticipACTION provided the guidelines and manuals for communities to host festivals (e.g. open houses, try-it days), competitions (e.g. sport tournaments), and fun events (e.g. Jersey Day) related to any kind or level of sport. Several promotional strategies were employed to increase public awareness of SDIC, including televised promotions aired by $\mathrm{CBC}$, social media advertisements, and electronic newsletters targeted to organizations. During the six years of SDIC initiatives (2010 to 2015), a total of 9763 events were hosted by 2854 communities (an average of 476 communities per year) in all provinces and territories. These events engaged 5,081,504 participants, spectators, and volunteers over the six years (an annual average of 847,000 ).

A longitudinal evaluation showed that population awareness of SDIC increased significantly between 2010 and 2013.28 Furthermore, intentions to participate in sport as a result of SDIC significantly increased over time among people who were aware of SDIC. Although the increased willingness to participate in sport and to become more healthy and active was found to be more evident among participants who were already "physically active" compared to their "inactive" counterparts, the program also promoted people who "never" participated in sports to increase their intention to participate in sport. A related study examined the benefits of organizations participating in SDIC between 2010 and 2013. ${ }^{24}$ There was self-reported evidence that participation in SDIC increased the profile of organizations to promote and deliver sport and physical activity opportunities within their communities, and had also attracted new participants to local sport and recreation centers or clubs. The results of these longitudinal analyses of SDIC suggest that large-scale special events have a role to play in encouraging sport participation, building community capacity, and facilitating healthy active living among Canadians. There is a further need, however, to identify how to reach inactive people more effectively and how to leverage sport events in their local communities throughout the year. The outcomes of the SDIC evaluation aided ParticipACTION in developing and implementing one initiative (the ParticipACTION 150 Play List which was launched in 2017).

\section{RBC Learn to Play}

"RBC Learn to Play" is ParticipACTION's first initiative that focuses on the principles of physical literacy and incorporating them into youth sport and recreation programs to enable youth in Canada to play, and become healthy and active for life. Launched in 2014, this three-year-long project has been initiated through various types of partnerships with a for-profit sponsor (RBC, as funder and title sponsor), non-profit organizations (the Public Health Agency of Canada, as funder and the Canadian Sport for Life, as implementation partner), and academic institutes (Propel Centre for Population Health Impact [https://uwaterloo.ca/propel], as evaluation partner; and the Healthy Active Living and Obesity Research Group [www .haloresearch.ca] as the research surveillance partner).

In conjunction with the launch of this initiative, ParticipACTION worked with sector partners to create a consensus definition of physical literacy (http:// physicalliteracy.ca/wp-content/uploads /2016/08/Consensus-Handout-EN-WEB _1.pdf). This consensus process was instrumental in providing a uniform understanding of physical literacy across multiple sectors in Canada (e.g. sport, physical activity, physical education, public health, recreation, research) and internationally (International Physical Literacy Association).

The center-piece of this initiative is a local community physical literacy development grant opportunity. Local organizations and communities such as sport clubs, municipal parks, recreational centers, schools, and aboriginal organizations who are eligible to apply for grants ranging from $\$ 1000$ to $\$ 25000$ have been receiving funding that supports program implementation, facility use, instruction, training, and project staffing. During the two years of its implementation (2014 - 2015), a total of $\$ 3.66$ million CAD in funding was allocated to over 380 organizations. ${ }^{29}$ In addition to the grants, grant recipients are provided supports including a physical 
literacy assessment tool and knowledge translation activities through webinars.

An evaluation of the RBC Learn to Play was conducted to understand the impact of the four core constructs of physical literacy (i.e. knowledge and understanding; motivation and confidence; physical competence; and daily physical activity behavior), and of the fundamental movement skills, on organizers as well as program participants. During two years of program implementation $^{30}, 88 \%$ of organizers who joined the program reported that their understanding of physical literacy improved after completing the training, and $97 \%$ of them stated they intended to integrate what they learned at the training into their work. Seventy-seven per cent of parents indicated that their awareness of physical literacy also increased. Though additional funding might be needed to achieve greater impact, the evaluation of the RBC Learn to Play demonstrates that the program is successful in improving community-level supports (e.g. policies, coalition building, advocacy work) and reducing barriers to program access by promoting inclusivity, minimizing cost and providing transportation. Current levels of physical literacy based on a large sample of Canadian children ( $>10000$ ) using the Canadian Assessment of Physical Literacy is also nearing completion as part of this initiative. $^{31,32}$ The evaluations have been used to identify strengths and areas for improvement for future initiatives undertaken by ParticipACTION and have informed the ParticipACTION Report Card. ${ }^{33}$

\section{Knowledge exchange}

Coalition-building, networking, and disseminating evidence-based knowledge were identified organizational priorities of the new ParticipACTION intended to enhance organizational capacity both internally (e.g. in leadership, infrastructure and will) ${ }^{34}$ and externally (e.g. in political climate, community awareness and interest, and existing inter-organizational partnerships).

\section{ParticipACTION Partner Network}

In 2011, ParticipACTION developed a Partnership Network with the goal of connecting with national and provincial sport organizations, and other for-profit and not-for-profit organizations, sharing their expertise with one another and gaining awareness of other initiatives and programs.
Members who enroll in the ParticipACTION Partner Network (PPN) have access to webinars, toolkits, and newsletters at no cost. The PPN currently includes 5005 registered organizations reflecting diverse engagement from the recreation, education, environment, and transportation sectors.

Ensuring that all of the information it provides is evidence-based, credible, and upto-date, ParticipACTION has built trust with the PPN organizations and helped them to access the country's top research in the area of physical activity and health. According to a network survey conducted in $2015^{35}, 90.5 \%$ of respondents agreed that ParticipACTION is a leader on physical activity issues in Canada for all age groups. Also, more than $80 \%$ of respondents agreed that ParticipACTION is successful in advancing and communicating knowledge on the issues associated with physical activity (85.6\%) and sedentary behaviours (80.2\%) among Canadians. Overall, the results demonstrate that ParticipACTION has become a knowledge exchange hub in a way that appears to be meeting the expectations of its PPN members.

\section{ParticipACTION Report Card}

The ParticipACTION Report Card on Physical Activity for Children and Youth (continuing the work of Active Healthy Kids Canada [see Tremblay et al., 2014 ${ }^{36}$ ]) is developed by ParticipACTION, in partnership with the Healthy Active Living and Obesity Group at the Children's Hospital of Eastern Ontario Research Institute, and represents Canada's most comprehensive assessment of child and youth physical activity including evidence-informed grades across 11 indicators related to daily behaviours, settings and sources of influence, and strategies and investments (see Barnes et al., in press for the most recent report card). ${ }^{33}$ The ParticipACTION Report Card Research Committee, constituted of experts from across Canada, provide guidance and leadership for the Report Card data collection and analysis, informing the grade assignment process, reviewing content, and assisting with its dissemination. In collaboration with the Report Card Research Committee, ParticipACTION has created a variety of resources (e.g. full and highlight reports, fact sheet, infographic, slide presentation, poster, media kit-see https://www.participaction.com/en-ca /thought-leadership/report-card/2016) for organizations to facilitate projects designed to improve indicators in the Report Card and to help Canadian kids to meet the physical activity guidelines. Each Report Card has received significant media attention. The 2016 Report Card received 223 million media impressions (ParticipACTION, personal communication).

In 2015, ParticipACTION worked with a coalition of organizations that developed a Position Statement on Active Outdoor Play $^{37}$ to integrate the Position Statement into the Report Card. This knowledge exchange and mobilization partnership yielded significant impact with > 300 million media impressions upon release (the greatest ever by the Report Card) and sustained social media dialogue. It also provoked a $\$ 2.7$ million investment by The Lawson Foundation to address the recommendations in the Position Statement (http://lawson.ca/outdoorplay). This knowledge exchange initiative proved to be an effective capacity building initiative as well.

Building off the success of the 2015 experience of embedding a "knowledge product” into the Report Card, ParticipACTION, in partnership with the Canadian Society for Exercise Physiology, the Conference Board of Canada, the Public Health Agency of Canada, and the Healthy Active Living and Obesity Research Group at the Children's Hospital of Eastern Ontario Research Institute, included the new Canadian 24-Hour Movement Guidelines for Children and Youth: An Integration of Physical Activity, Sedentary Behaviour, and Sleep in the 2016 Report Card. ${ }^{38}$ This arrangement again provided extensive profiling of the ParticipACTION Report Card while serving as an established distribution mechanism for the guideline developers- $\mathrm{a}$ win-win and a value-add for the sector.

\section{Assessing the impact of ParticipACTION: a unique opportunity}

Returning to the field to collect follow-up data after relaunch was informed by a number of issues. First, as described above, there was evidence that activities conducted by ParticipACTION might have an influence on the benchmarks we identified at baseline (including their social marketing campaigns and specific initiatives such as Teen Challenge and Sports Day in Canada); and external events that may influence population levels of physical 
activity. These included the launch of Active Canada 20/20, A Physical Activity Strategy and Change Agenda for Canada in the fall of $2012^{39}$; and the release of the new Canadian Physical Activity Guidelines (January, 2011; see ${ }^{17}$ ), the Canadian Sedentary Behaviour Guidelines for children and youth (February, 2011; see ${ }^{40}$ ), the Canadian Physical Activity Guidelines for the Early Years (aged 0-4 years; ${ }^{41}$ ), the Canadian Sedentary Behaviour Guidelines for the Early Years (aged 0-4 years; ${ }^{42}$ ), and the most recent Canadian 24-Hour Movement Guidelines for Children and Youth $^{38}$. ParticipACTION has played an important role as one dissemination messenger of these guidelines (as illustrated in ParticipACTION's Think Again campaign and the most recent Report Card on the Physical Activity of Children and Youth ${ }^{33}$ ).

Perhaps the most visible evidence of potential change in sector cohesion is the development of Active Canada 20/20, A Physical Activity Strategy and Change Agenda for Canada. In our baseline qualitative work, key stakeholders described a number of expectations they had for the new ParticipACTION. ${ }^{43}$ One was that ParticipACTION's advocacy role should include driving a broad physical activity agenda through the creation of a national physical activity policy. ParticipACTION led the development and consultation process for such a strategy that is designed to engage decision makers and rally the collaborative, coordinated and consistent efforts of all stakeholders at every level to reverse the decline in population physical activity levels. ${ }^{39}$

Accordingly, in terms of overall hypotheses, we may expect to see changes in awareness of ParticipACTION at both an individual and organizational level, and perhaps a change in organizational capacity to promote physical activity as a result of ParticipACTION's relaunch. This is the focus of the papers in this special issue. To maintain consistency, the baseline studies using the same theoretical frameworks were replicated. The first study assesses awareness and understanding of ParticipACTION at an individual level approximately seven to eight years after the relaunch of ParticipACTION. The survey consisted of a set of questions on the Physical Activity Monitor conducted by the Institute for Social Research at York University on behalf of the Canadian Fitness and Lifestyle Research Institute
(CFLRI) between February 2014 and May 2015. The details of this project and the findings of the baseline data collection are described in the paper by Spence and colleagues. ${ }^{44}$

The purpose of the organizational level research was to assess current awareness of organizations regarding ParticipACTION, and their capacity to mobilize and advocate for physical activity. Using an internet-based survey instrument, provincial and national organizations from a range of sectors (e.g. sport, recreation, public health, education) provided responses for a quantitative assessment of organizational awareness of ParticipACTION and their capacity for physical activity promotion. The findings from the quantitative analysis of these data are presented in the paper by Faulkner et al. ${ }^{45} \mathrm{~A}$ sample of respondents from the quantitative survey ${ }^{45}$ participated in a follow-up telephone interview to examine in more detail their organizational capacity for physical activity promotion, and the related barriers and facilitators, using qualitative research techniques. Findings of this study are reported by Ramanathan et al. ${ }^{46}$ Both these studies were completed in 2013 approximately six years after the relaunch of ParticipACTION and the collection of baseline data on organizational capacity. Overall, our findings need to be considered in light of findings that the proportion of Canadian children, youth and adults meeting physical activity guidelines has remained stable between the 20072009 and 2014-2015 administrations of the Canadian Health Measures Survey. ${ }^{47}$

\section{Conclusion}

This paper provides a summary of key initiatives of the 'new' ParticipACTION since its relaunch and sets the stage for the other papers in this special series. As part of a special issue, the papers describe a novel, comprehensive approach to setting up evaluations of national social marketing efforts to promote physical activity. These studies provide evidence regarding the short-term impact ParticipACTION has had on individual awareness and behaviour, and on organizational capacity, readiness and advocacy regarding physical activity. More broadly, these studies provide lessons for evaluating national physical activity initiatives in the form of a natural experiment.

\section{Acknowledgements}

This project was made possible by an operating grant from the Canadian Institutes of Health Research (MOP123491). Guy Faulkner holds a Canadian Institutes of Health Research-Public Health Agency of Canada (CIHR-PHAC) Chair in Applied Public Health.

\section{Conflicts of interest}

GF, MST and JCS serve on the ParticipACTION Research Advisory Group.

\section{Authors' contributions and statement}

GF conceptualized the design of the paper and wrote the initial draft. LY assisted in collating published reports on ParticipACTION initiatives. MST and JCS assisted with drafting and revising the paper. All authors have seen and approved the final manuscript.

The content and views expressed in this article are those of the authors and do not necessarily reflect those of the Government of Canada.

\section{References}

1. Ekelund U, Steene-Johannessen J, Brown WJ, et al. Does physical activity attenuate, or even eliminate, the detrimental association of sitting time with mortality? A harmonised metaanalysis of data from more than 1 million men and women. The Lancet. 2016;388(10051):1302-10.

2. Poitras VJ, Gray CE, Borghese MM, et al. Systematic review of the relationships between objectively measured physical activity and health indicators in school-aged children and youth. Appl Physiol, Nutr, Metab. 2016;41(6):S197-S239. doi: 10.1139 /apnm-2015-0663.

3. Warburton DE, Charlesworth S, Ivey A, Nettlefold L, Bredin SS. A systematic review of the evidence for Canada's Physical Activity Guidelines for Adults. Inter J Behav Nutr Phys Act. 2010;7(39):1-220. doi: 10.1186 /1479-5868-7-39. 
4. Colley RC, Garriguet D, Janssen I, Craig CL, Clarke J, Tremblay MS. Physical activity of Canadian children and youth: accelerometer results from the 2007 to 2009 Canadian Health Measures Survey. Health Rep. 2011; 22(1):15.

5. Colley RC, Garriguet D, Janssen I, Craig CL, Clarke J, Tremblay MS. Physical activity of Canadian adults: accelerometer results from the 2007 to 2009 Canadian Health Measures Survey. Health Rep. 2011;22(1):7-14.

6. O'Reilly N, Brunette MK. Privatesector-Not-for-profit Partnerships in the Sport and Physical Activity Contexts. International Journal of Sport \& Society. 2014;4(1). doi: 10.18848 /2152-7857/CGP/v04i01/53961.

7. Rootman I, Edwards P. The best laid schemes of mice and men...: ParticipACTION's legacy and the future of physical activity promotion in Canada. Can J Public Health. 2004; 95:S37-S44.

8. Bauman A, Madill J, Craig CL, Salmon A. ParticipACTION: this mouse roared, but did it get the cheese? Can J Public Health. 2004;95:S14-S9.

9. Knox M. Forewords. Can J Public Health. 2004;95(Suppl 2:S5).

10. Tremblay MS, Craig CL. ParticipACTION: Overview and introduction of baseline research on the "new" ParticipACTION. Int $\mathrm{J}$ Behav Nutr Phys Act. 2009;6(1):1. doi: 10.1186 /1479-5868-6-84.

11. Latimer-Cheung A, Murumets K, Faulkner G. ParticipACTION: The national voice of physical activity and sport participation in Canada. In: Pate R, Buchner D, editors. Implementing physical activity strategies. Champaign, IL: Human Kinetics; 2014. p. 61-70.

12. Spence JC, Brawley LR, Craig CL, et al. ParticipACTION: Awareness of the participACTION campaign among Canadian adults-Examining the knowledge gap hypothesis and a hierarchy-of-effects model. Int $\mathrm{J}$ Behav Nutr Phys Act. 2009;6(1):1. doi: 10.1186/1479-5868-6-85.
13. Plotnikoff RC, Todosijczuk I, Faulkner G, et al. ParticipACTION: Baseline assessment of the 'new ParticipACTION': A quantitative survey of Canadian organizational awareness and capacity. Int J Behav Nutr Phys Act. 2009 ;6(1):1. doi: 10.1186/1479-5868-6-86.

14. Faulkner G, McCloy C, Plotnikoff RC, et al. ParticipACTION: Baseline assessment of the capacity available to the'New ParticipACTION': A qualitative study of Canadian organizations. Int J Behav Nutr Phys Act. 2009; 6(1):1. doi: 10.1186/1479-5868-6-87.

15. McGuire WJ. Public communication as a strategy for inducing health-promoting behavioral change. Prev Med. 1984;13(3):299-319.

16. Craig CL, Bauman A, Latimer-Cheung A, et al. An evaluation of the My ParticipACTION Campaign to increase self-efficacy for being more physically active. J Health Comm. 2015;20(9): 995-1003. doi: 10.1080/10810730.2015 .1012240 .

17. Tremblay MS, Warburton DE, Janssen I, et al. New Canadian physical activity guidelines. Appl Physiol Nutr Metab. 2011;36(1):36-46. doi: 10.1139 /H11-009.

18. Faulkner G, Solomon V, Berry T, et al. Examining the potential disconnect between parents' perceptions and reality regarding the physical activity levels of their children. Journal of Applied Research on Children: Informing Policy for Children at Risk. 2014;5(1):9.

19. Deshpande S, Berry TR, Faulkner GE, et al. Comparing the influence of dynamic and static versions of media in evaluating physical-activity-promotion ads. Social Marketing Quarterly. 2015:1524500415599376.

20. Berry TR, Craig CL, Faulkner G, et al. Mothers' intentions to support children's physical activity related to attention and implicit agreement with advertisements. Int $\mathrm{J}$ Behav Med. 2014;21(1):131-8. doi: 10.1007/s12529 -012-9279-5.

21. Rhodes RE, Berry T, Craig CL, et al. Understanding parental support of child physical activity behavior. Am J Health Behav. 2013;37(4):469-77. doi: 10.5993/AJHB.37.4.5.
22. Jarvis JW, Rhodes RE, Deshpande S, et al. Investigating the role of brand equity in predicting the relationship between message exposure and parental support for their child's physical activity. Social Marketing Quarterly. 2014;20(2):103-15.

23. Gainforth HL, Jarvis JW, Berry TR, et al. Evaluating the ParticipACTION "Think Again” Campaign. Health Education \& Behavior. 2016;43(4): 434-41.

24. Luciani A, White L, Berry TR, Deshpande S, Latimer-Cheung A, O'Reilly N, et al. Sports Day in Canada: Examining the benefits for event organizers (2010-2013). International Journal of Health Promotion and Education. 2017; 55(2): 66-80. doi: 10.1080/14635240.2016.1217164.

25. ParticipACTION. Bring Back Play Report. 2015. Available from: https://www .participaction.com/sites/default/files /downloads/Participaction-Impact -Report-2015.pdf

26. ParticipACTION. Teen Challenge tools \& resources. 2016. Available from: https://www.participaction.com/en-ca /programs/participaction-teen-challenge

27. Tamminen KA, Faulkner G, Witcher CS, Spence JC. A qualitative examination of the impact of microgrants to promote physical activity among adolescents. BMC Public Health. 2014; 14(1):1. doi: 10.1186/1471-2458-14 $-1206$.

28. White L, Luciani A, Berry TR, et al. Sports day in Canada: a longitudinal evaluation. Inter $\mathrm{J}$ Health Promot Educ. 2016;54(1):12-23. doi: 10.1080 /14635240.2015.1050122.

29. ParticipACTION. Learn To Play Overview. 2016. Available from: https://www.participaction.com/sites /default/files/downloads/Participaction -RBCLearnToPlay-Evaluation2014_0.pdf

30. ParticipACTION. Are Canadian kids too tired to move? The ParticipACTION report card on physical activity for children and youth. 2016. Available from: https://www.participaction.com /sites/default/files/downloads/2016 \% 20ParticipACTION \% 20Report \% 20 Card \% 20-\%20Full\%20Report.pdf 
31. Francis CE, Longmuir PE, Boyer C, et al. The Canadian assessment of physical literacy: development of a model of children's capacity for a healthy, active lifestyle through a Delphi Process. J Phys Act Health . 2016; 13(2). doi: 10.1123/jpah.2014-0597.

32. Longmuir PE, Boyer C, Lloyd M, et al. The Canadian Assessment of Physical Literacy: methods for children in grades 4 to 6 ( 8 to 12 years). BMC Public Health. 2015;15(1):1.

33. Barnes J, Cameron C, Carson V, Chaput JP, Faulkner G, Janson K, et al. Results from the Canadian 2016 ParticipACTION report card on physical activity for children and youth. J Phys Act Health. 2016; 13 (Suppl 2): S110-S116. doi: 10.1123/jpah.2016-0300.

34. Smith C. A preliminary examination of organizational capacity for heart health promotion in Alberta's regional health authorities. Global Health Promo. 2001:40.

35. ParticipACTION. Report of Network Survey. 2016.

36. Tremblay MS, Barnes JD, Cowie BJ. Impact of the Active Healthy Kids Canada report card: a 10-year analysis. J Phys Act Health. 2014;11:S3-S20. doi: 10.1123/jpah.2014-0167.

37. Tremblay MS, Gray C, Babcock S, et al. Position statement on active outdoor play. Inter J Environ Res Public Health. 2015;12(6):6475-505. doi: 10.3390/ijerph120606475.

38. Tremblay MS, Carson V, Chaput J-P, et al. Canadian 24-Hour Movement Guidelines for Children and Youth: An Integration of Physical Activity, Sedentary Behaviour, and Sleep. Appl Physiol Nutr Metab. 2016;41(6):S311S327. doi: 10.1139/apnm-2016-0151.

39. Spence JC, Faulkner G, Bradstreet CC, Duggan M, Tremblay MS. Active Canada 20/20: A physical activity plan for Canada. Can J Public Health. 2016;106(8):E470-E3. doi: 10.17269 /cjph.106.5041.

40. Tremblay MS, LeBlanc AG, Janssen I, et al. Canadian sedentary behaviour guidelines for children and youth. Appl Physiol Nutr Metab. 2011;36(1): 59-64. doi: 10.1139/H11-012.
41. Tremblay MS, LeBlanc AG, Carson V, et al. Canadian physical activity guidelines for the early years (aged 0-4 years). Appl Physiol Nutr Metab. 2012;37(2):345-56. doi: 10.1139/h2012 -018 .

42. Tremblay MS, LeBlanc AG, Carson V, et al. Canadian sedentary behaviour guidelines for the early years (aged 0-4 years). Appl Physiol Nutr Metab. 2012;37(2):370-80. doi: 10.1139/h2012 -019 .

43. Faulkner G, McCloy C, Plotnikoff RC, Tremblay MS. Relaunching a national social marketing campaign expectations and challenges for the "New" ParticipACTION. Health Promotion Practice. 2011;12(4):569-76.

44. Spence JC, Faulkner G, Lee EY, et al. Awareness of ParticipACTION among Canadian adults: a seven-year crosssectional follow-up. Health Promot Chronic Dis Prev Can. 2018;38(4): 179-86.

45. Faulkner G, Ramanathan S, Plotnikoff RC, et al. ParticipACTION after 5 years of relaunch: a quantitative survey of Canadian organizational awareness and capacity. Health Promot Chronic Dis Prev Can. 2018;38(4):162-9.

46. Ramanathan S, Faulkner G, Berry T, et al. Perceptions of organizational capacity to promote physical activity in Canada and ParticipACTION's influence five years after its relaunch: a qualitative study. Health Promot Chronic Dis Prev Can. 2018;38(4): 170-8.

47. Statistics Canada (2017). Canadian Health Measures Survey: Activity monitor data. Ottawa: Statistics Canada. Accessed 8th September 2017. Available from: http://www.statcan.gc.ca /daily-quotidien/170419/dq170419e -eng.pdf 